\title{
Analysis of the Impact of Technological Advances Such as Big Data and Al on Gender Equity of People Management in Organisations
}

\author{
Yingwen Zhang * \\ School of Business and Management, Queen Mary University of London, London, UK \\ *yingwen.zhang@hss20.qmul.ac.uk
}

\begin{abstract}
With the advent of Industry 4.0, the development of intelligent technology solutions (ITS) such as big data and artificial intelligence (AI) has brought some changes to organisational people management. To further understand the impact of the development of ITS on gender equity in organisational people management, this paper analyses the positive and negative aspects of organisational people management equity in the context of rapid technological development from the perspective of women in three dimensions of human resource management: recruitment, performance management and compensation management, and proposes corresponding solutions to these impacts to provide some reference ideas for ensuring gender equity in organisational people management.
\end{abstract}

Keywords: Gender Equity; Organisational People Management; Artificial Intelligence; Bias.

\section{Introduction}

Many people worry that women cannot be competent for men in the same position or break through the 'glass ceiling' and achieve success, which is due to the undervaluation of the ability of women, that is stereotypes and bias on women. In the past, some scholars hold the view that segregation makes it more difficult to directly compare the skills or contributions of women and men, which may also conceal the impact of gender on salary differences between departments and organisations, as well as the pay and grades in organisations [1]. This segregation may lead to the division of jobs by gender, that is, women and men may be treated inequality when competing for the same position or in terms of pay and rank within the company because some positions may be considered more suitable for men, while women are not considered to be able to break the 'glass ceiling' and succeed. In Industry 4.0, technology is making continuous progress. With the development of the Internet, the emergence of advanced technology solutions such as big data and AI (referred to as intelligent technology solutions, ITS) is also driving the way of people management to become digital and intelligent. For example, ITS is integrated into the talent acquisition, performance appraisal and remuneration processes by using technology to reduce human intervention in order to improve the fairness of people management and increase the diversity and inclusiveness in organisations. The article analyses the impact of technological advances on women in organisations from the perspective of talent recruitment, performance appraisal and compensation management in human resource management. It shows that although technological advances cannot completely solve the problem of the underrepresentation of women in organisations and gender bias, technological advances will improve the fairness of the competition of women in the workplace to some extent. This article also argues that in addition to the development of Information Technology (IT), it is important to strengthen corporate cultural inclusiveness, transparency in decision-making and government policy intervention to avoid gender bias and inequality in people management.

\section{The Impact of Technological Development on Gender Equity}

\subsection{Positive Impacts}

Technological advances are beneficial to reduce the threat of unconscious bias against women and avoid gender inequality in talent acquisition. Many studies show that the ability to work for women 
has been underestimated for a long time because of unconscious bias and stereotypes towards women $[1,2,3,4]$. In other words, it is a common phenomenon that women are regarded as being far less competent than men at work. In terms of talent recruitment, the recruitment results will be affected when such unconscious biases and stereotypes are embedded in the minds of recruiters, which means recruiters may have negative perceptions of female candidates due to the unconscious biases and stereotypes towards women. The low evaluation of female candidates may cause a decrease in female employees and an imbalance in the gender ratio of the organisation, which will lead to inequitable recruitment results. For example, in 2020, Walmart excluded female applicants from order filler positions due to the gender bias against women. It believes that women are not as competent as men in the same position, which eventually resulted in gender discrimination and was sued accused the U.S. Equal Employment Opportunity Commission [5]. Today, with the development of Industry 4.0, technological advances provide more benefits for people management. Many organisations incorporate AI technologies such as machine learning into the recruitment process, including resume screening and evaluation [6]. AI has permeated companies and organisations and has improved the quality of people management and cost savings for organisations [7]. For example, applications such as Google Hire, Maimai and Boss Zhipin use AI to screen and manage job applicants, which not only improves the efficiency of candidate management and recruitment management but also avoids human intervention in the recruitment process. SAP uses a machine learning-based job description sentiment analysis model in its recruitment solution [8], which can effectively identify the potentially biased words in job descriptions and recommends alternative words to avoid bias. Moreover, Mujtaba and Mahapatra [9] show that using algorithms can develop a tool platform that effectively alleviates bias against women in the recruitment process. Compared with human decisions subject to human intervention, ITS-based recruitment methods can reduce bias. Fernández and Fernández [10] use machine learning algorithms to design a multi-agent system that uses AI to analyze video interviews processes to ensure the fairness of the interview as much as possible while reducing the conscious and unconscious bias of the interviewer. Therefore, ITS is conducive to promoting gender equality, which also shows that technological advances can reduce the bias against women in the recruitment process to some extent and ensure the fairness of gender equality in recruitment.

ITS in people management can ensure the fairness of employee performance-related appraisal results to some extent and help alleviate the under-representation of female employees in top management. Many scholars hold the view that employees can control the impression of performance appraiser to achieve high performance [11, 12, 13]. According to the research of Younis and Adel [14], traditional performance management is not objective because it involves emotional interaction between people. Unconscious gender biases are everywhere, and women in the workplace are always inevitably affected by unconscious gender biases or stereotypes. Filut et al. [15] believe that these biases affect the performance and promotion opportunities of females in the workplace. It is thought that single women are regarded to be more likely to get promoted than married women [16]. And due to gender bias, the number of female representatives in top management is far less than that of men $[17,18,19]$, and it is more difficult for women to achieve high performance and promote to senior management than men. Thus, traditional human resource performance management methods are susceptible to individual subjective influence. When performance appraisers have unconscious biases or stereotypes towards female employees, the fairness of performance-related appraisal results is difficult to guarantee, and the opportunities for women to be promoted to the core management in the organisation will be limited. With the advancement of technology, traditional performance management systems can no longer adapt to the current industry development in the context of big data [20]. Automated systems can help organisations record data accurately and objectively, and the application of ITS can also help organisations reduce daily performance appraisal errors. Studies have shown that an equal and objective performance appraisal system and standards can be developed to ensure fairness in the performance appraisal by AI algorithms and big data analysis [21, 22]. For example, SAP launched the Business Beyond Bias program in 2016, which embeds diversity, inclusiveness, and fairness in the corporate human resource process and uses ITS to reduce the bias 
in human resource management processes [23]. Thus, ITS can help to detect, prevent and reduce the bias and alleviate the impact of gender prejudice in the promotion and appraisal of female employees, which avoid women may not be promoted to top management due to gender bias and ensure fairness of the performance assessment and promotion to some extent.

The gender pay gap can be narrowed with the help of ITS. There is some evidence to show that the average income of females is much lower than that of males because females are prone to become discriminatory groups in the labour market in both developing and developed countries $[24,25,26$, 27]. The psychological research data of Lips [28] shows that most people have a bias in evaluating the contribution of women and promotion in the workplace, and Jordan et al. [29] believe that gender bias may lead to the gender pay gap. Therefore, eliminating bias against women is one of the ways to reduce the gender pay gap. In Industry 4.0, ITS can effectively analyse the historical salary data of employees and with the combination of AI algorithms to design calibration tools, which can avoid gender injustice and bias. For example, Fond uses IT to help companies narrow the gender pay gap. In the compensation management process, the cognitive robot designed by Fond can reveal any pay gaps to avoid the risk of human error or bias [30]. The calibration tool in SuccessFactors Compensation designed by SAP can calibrate employee compensation and expose unconscious bias in compensation decisions through ITS [23]. The salary management team in Hero Group analyses historical salary data through ITS, and alerts will appear when there is an unfair or prejudiced salary [31]. According to the research of Abdeldayem and Aldulaimi [32], programs designed by AI can maintain the fairness and justice of compensation management to some extent. Therefore, with the development of technology, the investment of ITS can prevent a series of unfair phenomena such as the reduction of women pay due to bias to some extent, thereby narrowing the gender pay gap.

\subsection{Negative Impacts}

However, although the advancement of ITS can maintain the fairness of people management in organisations and protect the rights of female employees to a certain extent, some additional attributes brought by technological development, such as high-intensity work pressure further reduce the proportion of female employees, which results in a serious imbalance between males and females in the technology industry. A report from Deloitte [33] states that although more than half of the workers in the U.S. are women in 2020, women in the IT industry account for only $25 \%$ and the employee turnover rate of women is also higher than that of men. According to a study from British Chartered IT Association BCS [34], compared with previous years, although the proportion of women engaged in the IT industry increased in 2020, female workers also account for only $20 \%$ of the IT industry and female workers are still under-represented in the IT workforce. Therefore, it seems that it is not rare for women to be underrepresented in the IT industry. The research of Gupta and Rao [35] shows that the factors that affect female workers work in the IT industry include workload and gender discrimination. The IT industry is intense and due to gender bias and stereotypes, women are usually considered to be the primary role of housewives, and due to the high intensity of work pressure in the IT industry, some married female applicants may be regarded as those who are unable to balance work and family, so that women are not prioritized in interviews or promotion $[16,35,36]$. As a result, some women are excluded from the IT industry. Similarly, most female workers attach great importance to balancing work and family [36]. The high-intensity work pressure in the IT industry may cause female workers to fail to balance family and work, so that female workers are reluctant to pursue a career in the IT industry. Facing the high turnover in the IT industry [36], to accelerate technological innovation and increase technological productivity, it is important to increase the number of female workers who are underrepresented in the IT industry. Therefore, addressing the gender imbalance in the IT industry requires alleviating concerns from women about the high work pressure in the IT industry and the gender bias.

In addition, tool systems designed based on AI models, such as machine learning models and deep learning models may have a gender bias in calculations due to the insufficient amount of femalerelated data included in the training dataset. Fernández \& Fernández [10] states that the decision- 
making of the intelligent recruitment system may also be wrong. For example, applying a learning algorithm trained on white datasets to black recruitment will lead to racial bias. Moreover, it is reported that Amazon abandoned an AI recruitment tool that was developed in 2014 because it discriminated against women [37]. The IT industry has always been dominated by male workers and since the training dataset used by Amazon is mainly derived from the resumes received by the company in the past decade, the number of male resumes in the training data set is much more than female resumes. The pre-trained intelligent recruitment system will be more biased towards men due to imbalanced data samples, resulting in female applicants are scored lower than male applicants. Therefore, the accuracy of the tool system designed by relying on AI is likely to be affected by the training data. When the training data is under-represented or the training samples are unbalanced, it is easy to cause deviations in the results.

\section{Solutions}

The gender bias caused by the problem of unbalanced sample data can be solved by increasing the amount of female-related data and balancing the sample distribution. Since the resumes received by Amazon in the past ten years are mainly male resumes, when doing sample training, the proportion of male samples can be deducted, and the number of female samples can be added accordingly to keep balance. When the amount of data between men and women in the sample reaches a 1:1 equilibrium, the accuracy of the training results can be improved, thus avoiding the bias of the AI recruitment system towards women. Hence, deviations influenced by human intervention require several calibrations, tests and even audits by various parties to avoid recurrence, such as setting up policy and professional institutions to audit and issue the qualified qualifications, and software can only be published by the qualified qualifications.

In addition to addressing gender bias through technology, companies can also strengthen the inclusiveness and diversified culture in organisations. According to the research of McKinsey, diverse teams can detect, predict and avoid bias better. Companies not only need to eliminate bias in recruitment, but also in performance evaluation to ensure fairness [38]. In talent acquisition and performance management, organisations should demonstrate inclusivity towards women. For example, increasing the number of female employees or married female employees, providing promotion opportunities for female or married female employees, and avoiding gender discrimination. Williams [38] also mentioned that managers in organisations need to have in-depth and sincere communication with employees regularly to show caring and inclusiveness to disadvantaged groups. In some industries with high workloads, organisations can increase welfare leave for pregnant employees to reduce work stress, allowing pregnant employees to get adequate rest before giving birth and sufficient time to balance work and family afterwards. Besides, activities such as mother class can be organised regularly so that female employees will feel cared to reduce pressure and prejudice.

Moreover, companies should increase the transparency of decision-making in people management to prevent unfairness. For example, show the decision-making process to all members to help employees to understand the reason of decisions when making decisions in the organisation. By improving the transparency of decision-making, it makes all members be supervisors of the decision to avoid inequality.

Finally, policy support from the government is essential to alleviate the gender imbalance of labour caused by technological development. The research of Kaminski and Reilly [36] shows that most female employees are pay attention to the family and hope to balance work and family well and obtain equal employment opportunities. The government can have policy support, such as increasing the maternity leave for female workers to balance work and family. In terms of legislation, many countries such as China and the United Kingdom have clearly prohibited companies from expelling pregnant employees, so pregnant employees will be protected and can take care of family, and ease 
the pressure caused by family and work. The relief of family pressure will be beneficial for women to engage in work to some extent.

\section{Conclusion}

In conclusion, this article analyses the impact of technological advances such as big data and AI on the fairness of women in people management in terms of recruitment, performance and promotion assessment, and salary distribution in organisations. It shows that in Industry 4.0, the advancement of the Internet and technology promotes the integration of ITS in-people management, which allows organisations to make more use of technology in recruitment, promotion and assessment, and salary distribution to reduce the bias and stereotypes of women caused by human intervention in the workplace, avoid inequalities and increase the standardization and fairness of employment. In the meanwhile, this article discusses the limitations of technological advances on people management. Although technological advances can ensure the fairness of people management to some extent, the imbalance between men and women in organisations may still occur, and AI system tools may also be biased because of the human factors in the pre-training period. All in all, technological advancements provide organisations with effective tools to ensure fairness in people management, which reduces the unequal treatment that women used to suffer from due to gender bias or stereotypes. However, to ensure the fairness of people management, increase the proportion of female representatives in the top management, and avoid bias, organisations need to increase the transparency of decision-making and cultural inclusion. For example, holding regular cultural inclusion events and placing inclusion at the core of talent development strategies. In addition, government intervention is one of the effective ways to ensure that women are not treated unfairly in the workplace. The social rights of women can be protected by legal protection and policy support, which can protect women from inequality.

\section{References}

[1] Grimshaw, Damian, and Jill Rubery. Undervaluing women's work. Manchester: Equal Opportunities Commission, 2007.

[2] Raymond, Jennifer. "Most of us are biased." Nature 495, no. 7439 (2013): 33-34.

[3] Eagly, Alice H., and Steven J. Karau. "Role congruity theory of prejudice toward female leaders." Psychological review 109, no. 3 (2002): 573.

[4] Rhode, Deborah L. "Gender stereotypes and unconscious bias." In Handbook of research on gender and leadership. Edward Elgar Publishing, 2017.

[5] Information on: https://www.eeoc.gov/newsroom/walmart-inc-pay-20-million-settle-eeoc-nationwidehiring-discrimination-case.

[6] Rana, Ahmed Nauraiz. "Leveraging Big Data to Advance Gender Equality." (2020).

[7] Mesko, Bertalan. "The role of AI in precision medicine." Expert Review of Precision Medicine and Drug Development 2, no. 5 (2017): 239-241.

[8] Information on: https:// news. sap. com/ 2016/08/ sap-reveals-new-technology-designed-to-help-movebusiness-beyond-bias/.

[9] Mujtaba, Dena F., and Nihar R. Mahapatra. "Ethical considerations in ai-based recruitment." In 2019 IEEE International Symposium on Technology and Society (ISTAS), pp. 1-7. IEEE, 2019.

[10] Fernández, Carmen, and Alberto Fernández. "Ethical and legal implications of ai recruiting software." Ercim News 116 (2019): 22-23.

[11] Bolino, Mark C., José A. Varela, Belén Bande, and William H. Turnley. "The impact of impressionmanagement tactics on supervisor ratings of organisational citizenship behavior." Journal of Organisational Behavior: The International Journal of Industrial, Occupational and Organisational Psychology and Behavior 27, no. 3 (2006): 281-297. 
[12] Bolino, Mark, David Long, and William Turnley. "Impression management in organisations: Critical questions, answers, and areas for future research." Annual Review of Organisational Psychology and Organisational Behavior 3 (2016): 377-406.

[13] Bande, Belen, Pilar Fernández-Ferrín, Carmen Otero-Neira, and José Varela. "Impression management tactics and performance ratings: A moderated-mediation framework." Journal of Business-to-Business Marketing 24, no. 1 (2017): 19-34.

[14] Younis, Raghda Abulsaoud Ahmed, and Heba Mohamed Adel. "AI strategy, creativity-oriented HRM and knowledge-sharing quality: Empirical analysis of individual and organisational performance of AIpowered businesses." In Proceedings of the Annual International Conference of The British Academy of Management (BAM). 2020.

[15] Filut, Amarette, Anna Kaatz, and Molly Carnes. "The impact of unconscious bias on women's career advancement." The Sasakawa Peace Foundation Expert Reviews Series on Advancing Women's Empowerment (2017).

[16] Hill, Catherine, Christianne Corbett, and Andresse St Rose. Why so few? Women in science, technology, engineering, and mathematics. American Association of University Women. 1111 Sixteenth Street NW, Washington, DC 20036, 2010.

[17] Hoyt, Crystal L. "Women, men, and leadership: Exploring the gender gap at the top." Social and personality psychology compass 4, no. 7 (2010): 484-498.

[18] Hill, Catherine, Kevin Miller, Kathleen Benson, and Grace Handley. "Barriers and Bias: The Status of Women in Leadership." American Association of University Women (2016).

[19] Evans, Kathryn J., and Jane F. Maley. "Barriers to women in senior leadership: how unconscious bias is holding back Australia's economy." Asia Pacific Journal of Human Resources 59, no. 2 (2021): 204-226.

[20] Fu, Honglin. "Optimization Study of Multidimensional Big Data Matrix Model in Enterprise Performance Evaluation System." Wireless Communications and Mobile Computing 2021 (2021).

[21] Singh, Abhilasha, and Apurva Shaurya. "Impact of AI on HR practices in the UAE." Humanities and Social Sciences Communications 8, no. 1 (2021): 1-9.

[22] Haenlein, Michael, and Andreas Kaplan. "A brief history of AI: On the past, present, and future of AI." California management review 61, no. 4 (2019): 5-14.

[23] Information on: https:// news. sap. com/ 2020/07/ fighting-workplace-discrimination-a-commitment-tobuilding-business-beyond-bias/.

[24] Blau, F. D., and L. M. Kahn. "The gender gap: Have women gone as far as they can." Academy of Management Perspectives 21, no. 1 (2007): 7-23.

[25] Blau, Francine D., and Lawrence M. Kahn. "Understanding international differences in the gender pay gap." Journal of Labor economics 21, no. 1 (2003): 106-144.

[26] Blau, Francine D., and Lawrence M. Kahn. "Analyzing the gender pay gap." The Quarterly Review of Economics and Finance 39, no. 5 (1999): 625-646.

[27] Talafheh, Qusi. "Pay inequality between the two genders." PhD diss., University of Kent, 2020.

[28] Lips, Hilary M. "The gender pay gap: Concrete indicator of women's progress toward equality." Analyses of Social Issues and Public Policy 3, no. 1 (2003): 87-109.

[29] Jordan, Charles E., Stanley J. Clark, and Marilyn A. Waldron. "Gender bias and compensation in the executive suite of the Fortune 100." Journal of Organisational Culture, Communications and Conflict 11, no. 1 (2007): 19.

[30] Information on: https://www.fond.co/blog/5-ways-diversity-and-inclusion-technology/.

[31] Information on: https:// www. forbes. com/ sites/ sap/ 2021/ 06/28/ how-technology-supports-workplacediversity-equity-and-inclusion/?sh=1e4eeb6128b8.

[32] Abdeldayem, Marwan Mohamed, and Saeed Hameed Aldulaimi. "Trends and opportunities of AI in human resource management: Aspirations for public sector in Bahrain." International Journal of Scientific and Technology Research 9, no. 1 (2020): 3867-3871.

[33] Information on: Information on: https://deloitte.wsj.com/articles/.

[34] Information on: https://www.bcs.org/about-us/press-office/press-releases/record-numbers-of-women-init-but-black-women-still-under-represented-new-research-finds/. 
[35] Gupta, Chhavi, and K. V. S. R. Rao. "A Conceptual Framework \& Analysis of Work-life Balance Challenges of Women Professionals in the IT Industry." International Journal of Latest Technology in Engineering, Management \& Applied Science-IJLTEMAS 1, no. 6 (2019): 32-37.

[36] Kaminski, Jennifer A. Muryn, and Anne H. Reilly. "Career development of women in information technology." SAM Advanced Management Journal 69, no. 4 (2004): 20.

[37] Information on: https://fortune.com/2018/10/10/amazon-ai-recruitment-bias-women-sexist/.

[38] Joan C. Williams. Bias Interrupted: Creating Inclusion for Real and for Good. Harvard Business Review, 2021. 